\title{
PENGARUH FAKTOR KEPUASAN KERJA TERHADAP EMPLOYEE ENGAGEMENT DI PERWIRATAMA GROUP
}

\section{THE IMPACT OF JOB SATISFACTION TOWARDS EMPLOYEE' ENGAGEMENT (STUDY CASE IN PERWIRATAMA GROUP)}

\author{
Windy Putri Arianti ${ }^{*}$, Musa Hubeis 1 , \& Herien Puspitawati ${ }^{1}$ \\ 'Program Magister Manajemen Bisnis, Sekolah Bisnis, Institut Pertanian Bogor \\ Alamat: Jalan Raya Pajajaran, Babakan, Bogor, Jawa Barat 16128 \\ *E-mail: windyputriarianti3@gmail.com
}

\begin{abstract}
ABSTRAK
Perwiratama Group adalah salah satu perusahaan dalam industri bisnis yang harus bersaing dengan perusahaan lain dalam segmentasi yang sama. Salah satu cara untuk bersaing adalah dengan mengetahui faktor-faktor kepuasan kerja dan keterlibatan karyawan di Perwiratama Group. Variabel dalam penelitian ini adalah faktor kepuasan kerja dan keterlibatan karyawan. Responden dari penelitian ini adalah 84 karyawan Perwiratama Group di empat unit bisnis. Metode penelitian yang digunakan adalah regresi linier berganda. Hasil penelitian ini menunjukkan bahwa variabel kepuasan kerja pada pekerjaan, kepuasan kerja pada gaji dan kepuasan kerja pada rekan kerja mempengaruhi variabel keterlibatan karyawan. Sedangkan variabel kepuasan kerja pada promosi dan kepuasan kerja pada pengawasan variabel keterlibatan karyawan tidak berpengaruh. Hasil Adjusted R Square adalah 0,431 atau $43,1 \%$. Nilai ini menunjukkan bahwa variabel faktor kepuasan kerja (kepuasan kerja di tempat kerja, kepuasan kerja pada gaji, kepuasan kerja pada promosi, pengawasan kepuasan kerja, dan kepuasan kerja pada kolega) mempengaruhi variabel keterlibatan karyawan di Perwiratama Group sebesar $43,1 \%$, sedangkan sisanya dipengaruhi oleh faktor-faktor lain yang tidak diteliti dalam penelitian ini.
\end{abstract}

Kata kunci: kepuasan dengan pekerjaan, kepuasan dengan gaji, kepuasan dengan promosi, kepuasan dengan pengawasan, kepuasan dengan rekan kerja, keterlibatan karyawan

Klasifikasi JEL: D23, J28, M51

\begin{abstract}
Perwiratama Group is one of the companies in the business industry that must compete with another company in the same segmentation. One way to compete is by knowing the factors of job satisfaction and employee engagement at Perwiratama Group. These variables are job satisfaction factors and employee engagement. Respondents of this study were 84 employees of Perwiratama Group in four business units. The research method used is multiple linear regression. The result of this study shows that job satisfaction variable on work, job satisfaction on salary, and job satisfaction on co-workers influence employee engagement variables. While job satisfaction variables on promotion and job satisfaction on supervision of employee engagement variables have no effect. Adjusted $R$ Square results are 0.431 or 43.1\%. This value shows that the variables of job satisfaction factors (job satisfaction at work, job satisfaction on salary, job satisfaction on promotion, supervision of job satisfaction, and job satisfaction on colleagues) affect employee engagement variables at Perwiratama Group by $43.1 \%$, while the rest is influenced by other factors not examined in this study.
\end{abstract}

Keywords: satisfaction with the job, satisfaction with the salary, satisfaction with promotion, satisfaction with the supervision, satisfaction with coworkers, employee engagement

JEL Classifications: D23, J28, M5 1

Article History:

Received : August 19, 2019; Revised : April 17, 2020; Accepted : April 19, 2020; Available Online : April 26, 2020 DOI: $\underline{10.20473 / \text { imtt.v13i1.14889 }}$

CWindy Putri Arianti, Musa Hubeis, Herien Puspitawati. Published in Jurnal Manajemen Teori dan Terapan. Published by Universitas Airlangga, Department of Management. This article is published under the Creative Commons Attribution (CC BY 4.0) licence. 


\section{PENDAHULUAN}

Globalisasi merupakan proses integrasi sosial, politik, ekonomi, budaya, dan teknologi antara negara-negara di seluruh dunia. Globalisasi terjadi sangat cepat, menciptakan peluang dan tantangan bagi bisnis global (Luthans, 2006). Agar perusahaan yang menggeluti di industri bisnis tersebut mampu mengatasi perubahan yang terjadi, maka diperlukan Sumber Daya Manusia (SDM) yang optimal. SDM adalah sumber yang menggerakkan dan mengarahkan organisasi serta mempertahankan dan mengembangkan organisasi dalam berbagai tuntutan masyarakat dan zaman sehingga SDM dapat dikatakan sebagai aset yang paling penting dalam suatu organisasi baik dalam skala besar maupun kecil (Susilo \& Abdul, 2015). Tanpa adanya SDM, perusahaan akan tidak mempunyai arti, meskipun perusahaan tersebut memiliki berbagai sumber daya lainnya seperti mesin baru, modal banyak, energy melimpah, dan lainnya, semua akan menjadi sia-sia jika tidak dikelola dan dijalankan dengan baik oleh SDM (Affini \& Surip, 2018).

Banyak kalangan berpendapat bahwa employee engagement harus menjadi perhatian serius oleh eksekutif bidang SDM maupun eksekutif puncak agar perusahaan dapat bertahan dari dampak krisis yang dihadapi (Mujiasih \& Ratnaningsih, 2011). Berbagai penelitian telah dilakukan dan menunjukan employee engagement merupakan kontributor yang sangat penting dari keberhasilan suatu perusahaan. Studi dari Gallup (2006) terhadap ratusan perusahaan menunjukan 54\% dari karyawan termasuk kategori disengaged (tidak memiliki "keterikatan" dengan pekerjaannya), dan $17 \%$ dalam kategori actively disengaged, yaitu tidak memiliki keterikatan, bahkan lebih jauh lagi, tidak secara aktif untuk menularkan sikap negatif, bersikap destruktif dan memusuhi organisasi, serta $29 \%$ karyawan memiliki keterikatan dengan tempat kerjanya (Coffman et al., 2002).

Menurut penelitian yang dilakukan Gallup (2006), tingkat engagement yang tinggi akan memberikan keuntungan kepada perusahaan tempatnya bekerja $12 \%$. Akan menjadi masalah, jika di suatu perusahaan memiliki keterikatan karyawan rendah. Menurut Finney, karyawan yang tidak memiliki keterikatan sangat mahal dan merusak. Di Amerika Serikat, hal tersebut dianggap merugikan organisasi/perusahaan senilai 350 milyar dollar karena rendahnya produktivitas (Maarif \& Kartika, 2014).

Kepuasan kerja mempunyai hubungan erat dengan employee engagement. Karyawan yang memperoleh kepuasan kerja mempunyai potensi besar untuk keterikatan karyawan (employee engagement) dengan perusahaannya. Pengaruh tingkat kepuasan kerja terhadap tingkat engagement karyawan berpengaruh positif, artinya semakin tinggi tingkat kepuasan kerja karyawan, maka semakin tinggi tingkat engagement karyawannya (Kari, 2013). Karyawan yang puas dan termotivasi akan peduli, merasa memiliki, atau 


\section{Windy Putri Arianti \\ Musa Hubeis \\ Herien Puspitawati}

mengabdikan diri terhadap bisnis organisasi secara maksimal dan bekerja secara tim guna meningkatkan performance bagi perusahaan (Yuswardi, 2019). Kertriasih et al. (2018) berpendapat jika karyawan merasa puas di tempatnya bekerja maka akan menimbulkan perasaan engaged pada pegawai tersebut sehingga dapat bekerja secara optimal. Selaras dengan pendapat tersebut, Garg et al. (2018) pun menyatakan bahwa kepuasan kerja mempunyai hubungan yang positif dengan employee engagement. Selain itu juga, Maarif dan Kartika (2014) menyatakan kepuasan kerja merupakan sikap, perasaan, perilaku seseorang terhadap faktor-faktor pekerjaan dan lingkungan pekerjaannya, serta interaksi individu di luar pekerjaannya.

Sama halnya dengan Perwiratama Group untuk mencapai tujuan perusahaan. Perwiratama Group juga mengadopsi sistem sumber daya manusia yang sedang hangat diperbincangkan yaitu kepuasan kerja yang mana mempunyai hubungan erat dengan tercapainya proses pegawai menjadi engaged. Perwiratama Group merupakan perusahaan dibidang agricultural yang masih merintis dan memiliki beberapa business units dibidang infrastructure, production, processing, logistic \& distribution, digital channel, dan consulting harus memikirkan cara agar dapat bertahan, bahkan bersaing di industri bisnis.

Penelitian ini bertujuan untuk menganalisis faktor kepuasan kerja karyawan sehinggaemployee engagement di Perwiratama Groupmenjadi lebih baik. Kepuasan kerja ini tidak hanya dianalisis secara umum namun juga lebih mendalam berdasarkan faktorfaktor yang memengaruhi kepuasan kerja itu sendiri dengan terperinci. Dengan demikian, berdasarkan hasil penelitian ini diharapkan dapat memberikan masukan kebijakan pengelolaan SDM terkait peningkatan employee engagement. Ruang lingkup penelitian ini meliputi empat unit usaha perusahaan Perwiratama Group, yaitu PT Arwinda Perwira Utama, PT Cipta Ekspedisi Perwiratama, PT Solusi Pangan Perwiratama, PT Cipta Kuliner Perwiratama dan dengan peubah penelitian yang akan diteliti adalah employee engagement dan faktor-faktor kepuasan kerja.

\section{LANDASAN TEORI}

\section{Employee Engagement}

Employee engagement merupakan keterlibatan, kepuasan dan antusiasme individual dengan kerja yang dilakukan (Robbins \& Judge, 2015). Macey et al. (2009) mendefinisikan employee engagement sebagai perasaan individu terhadap tujuan dan energi terfokus jelas, bagi orang lain dalam tampilan inisiatif pribadi, kemampuan beradaptasi, usaha dan ketekunan yang diarahkan pada tujuan organisasi. The Gallup Organization 
mengemukakan bahwa keterikatan karyawan adalah keterlibatan dengan antusiasme untuk bekerja (Maarif \& Kartika, 2014).

\section{Tingkatan Employee Engagement}

Gallup (2006) mengatakan bahwa ada tiga jenis karyawan dilihat dari tingkat ketertarikannya terhadap perusahaan, yaitu:

1. Karyawan yang terlibat (Engaged)

Karyawan yang memiliki keterikatan dengan perusahaannya akan semangat dan merasakan hubungan mendalam terhadap tempatnya bekerja

2. Karyawan yang tidak terlibat (Not Engaged)

Karyawan yang tidak memiliki keterikatan dengan perusahaan tidak akan memberikan banyak kontribusi kepada perusahannya dan bekerja dengan selalu memikirkan waktu berakhirnya jam kerja.

3. Karyawan yang tidak aktif (Actively Disengaged)

Karyawan yang pada kategori ini akan menunjukan sikap ketidaksukaannya terhadap pekerjaan yang dibebankan kepadanya, hingga mengacuhkan pekerjaan karyawan lain yang memiliki keterikatan dan memberikan pengaruh buruk kepada karyawan lain.

\section{Dimensi Employee Engagement}

Gallup (2006) mengatakan untuk indikator employee engagement dalam 12 pernyataan tersebut, memiliki empat dimensi (Fleming \& Asplund 2007). Indikator-indikator tersebut, adalah:

1. Tingkatan terbawah: What do I get?. Pada tingkatan ini tergantung kepada apa yang akan diperoleh seseorang dalam pertukaran untuk melakukan pekerjaan tersebut.

2. Tingkatan kedua: What do I give?. Karyawan pada tingkat ini memahami apa yang sebenarnya diharapkan darinya terhadap organisasi.

3. Tingkatan ketiga: How do I belong?. Di tingkat ini, karyawan ingin tinggal lebih lama dengan organisasi yang telah memperlakukannya sebagai bagian dari internal organisasi.

4. Tingkatan teratas: How can we grow?. Pada tingkat ini, karyawan mengharapkan terjadinya pertumbuhan berlanjut, termasuk promosi, kenaikan gaji dan juga penghargaan terhadap dirinya yang telah memberikan kontribusi bagi organisasi.

\section{Kepuasan Kerja}

Menurut Umar (2008) menyatakan bahwa kepuasan kerja adalah perasaan dan penilaian seorang atas pekerjaannya, khususnya mengenai kondisi kerjanya, dalam hubungannya dengan apakah pekerjaannya mampu memenuhi harapan, kebutuhan, dan keinginannya. Begitu pula dengan Watson yang mendefinisikan kepuasan kerja sebagai tingkat perasaan 


\section{Windy Putri Arianti \\ Musa Hubeis \\ Herien Puspitawati}

yang menyenangkan yang diperoleh dari penilaian pekerjaan seseorang atau pengalaman kerja (Wibowo, 2015). Untuk itu, dapat disimpulkan bahwa kepuasan kerja adalah tingkat perasaan dan penilaian atas pekerjaan seseorang terhadap pemenuhan kebutuhan dan keinginannya.

\section{Faktor-Faktor Kepuasan Kerja}

Luthans (2006) mengemukakan faktor-faktor yang dapat memengaruhi kepuasan kerja karyawan adalah gaji, karakteristik pekerjaan, promosi, supervisi, kelompok kerja, dan kondisi kerja. Menurut Colquitt et al.,kepuasan kerja memiliki beberapa kategori (Wibowo, 2015), yaitu:

1. Pay satisfaction, yaitu mencerminkan perasaan pekerja mengenai bayarannya yang sesuai dengan hak yang didapatkan;

2. Promotion Satisfaction, yaitu mencerminkan perasaaan pekerja mengenai kebijakan promosi perusahaan dan pelaksanaannya;

3. Coworker Satisfaction, yaitu mencerminkan perasaan karyawan terhadap rekan kerjanya;

4. Satisfaction with the work itself, yaitu mencerminkan perasaan pekerja mengenai pekerjaannya, apakah menantang atau sebagainya.

\section{Kajian Penelitian Terdahulu}

Penelitian terdahulu sangat penting sebagai dasar pijakan dalam rangka penyusunan penelitian untuk mengetahui hasil yang telah dilakukan oleh peneliti terdahulu, sekaligus sebagai perbandingan dan gambaran yang dapat mendukung kegiatan penelitian berikutnya. Berdasarkan kajian pada beberapa penelitian terdahulu, penelitian ini memiliki kesamaan peubahterikat dan peubah bebas yang diteliti, sehingga hasil penelitian ini dapat mendukung hasil temuan yang sudah ada sebelumnya. Namun, penelitian ini memiliki perbedaan dari segiobyek penelitian, alat analisis, dan indikator-indikator yang digunakan untuk mengukur setiap peubah.

Pada penelitian ini digunakan peubah employee engagement dengan indikator dari Gallup (2006) yang mengembangkan dan mengidentifikasi manjadi 12 pernyataan penting dan peubah kepuasan kerja dengan indicator dari Luthans (2006). Obyek dalam penelitian ini adalah seluruh karyawan Perwiratama Group dan teknik pengolahan data analisis regresi linear berganda untuk menguji pengaruh masing-masing peubah. 
Tabel 1.

Kajian penelitian terdahulu (lanjutan)

\begin{tabular}{|c|c|c|c|}
\hline $\begin{array}{l}\text { Nama Peneliti dan } \\
\text { Tahun Penelitian }\end{array}$ & Judul Penelitian & Metode & Hasil Penelitian \\
\hline $\begin{array}{l}\text { Anggraini et al. } \\
\text { (2016) }\end{array}$ & $\begin{array}{l}\text { Faktor-Faktor yang } \\
\text { mempengaruhi Employee } \\
\text { Engagement Generasi Y } \\
\text { (Studi Kasus Pada } \\
\text { Karyawan PT Unilever } \\
\text { Indonesia Tbk-Surabaya) }\end{array}$ & $\begin{array}{l}\text { Analisis } \\
\text { Regresi Linier } \\
\text { Berganda }\end{array}$ & $\begin{array}{l}\text { Terdapat pengaruh yang } \\
\text { positif dan signifikan dari } \\
\text { peubah budaya } \\
\text { organisasi, reward, dan } \\
\text { personal resources } \\
\text { terhadap peubah } \\
\text { employee engagement } \\
\text { yang dimiliki oleh Gen Y. }\end{array}$ \\
\hline $\begin{array}{l}\text { Kaliannan dan } \\
\text { Narch (2015) }\end{array}$ & $\begin{array}{l}\text { Effective Employee } \\
\text { Engagement and } \\
\text { Organizational Success: A } \\
\text { Case Study Mobile } \\
\text { Telecommunication } \\
\text { Network in Ghana }\end{array}$ & $\begin{array}{l}\text { Description } \\
\text { Method }\end{array}$ & $\begin{array}{l}\text { HRM practices, work } \\
\text { environment, employee } \\
\text { supervisor relationship, } \\
\text { job satisfaction, and } \\
\text { organizational culture } \\
\text { adalah faktor-faktor } \\
\text { yang memengaruhi } \\
\text { employee engagement } \\
\text { sehingga meningkatkan } \\
\text { kinerja. }\end{array}$ \\
\hline Katili et al.(2017) & $\begin{array}{l}\text { Analisis Pengaruh } \\
\text { Employee Competence, } \\
\text { Job Satisfaction dan } \\
\text { Employee Engagement } \\
\text { Terhadap Employee } \\
\text { Performance }\end{array}$ & $\begin{array}{l}\text { Structural } \\
\text { Equation } \\
\text { Modeling } \\
\text { (SEM) } \\
\text { dengan } \\
\text { menggunak } \\
\text { an software } \\
\text { LISREL }\end{array}$ & $\begin{array}{l}\text { Job satisfaction } \\
\text { berpengaruh positif } \\
\text { terhadap employee } \\
\text { engagement dengan } \\
\text { nilai sebesar } 0,95 \text {. }\end{array}$ \\
\hline Vorina et al. (2017) & $\begin{array}{l}\text { An Analysis of The } \\
\text { Relationship Between Job } \\
\text { Satisfaction and Employee } \\
\text { Engagement }\end{array}$ & $\begin{array}{l}\text { Analisis Linier } \\
\text { Regresi dan } \\
\text { ANOVA }\end{array}$ & $\begin{array}{l}\text { Kepuasan kerja } \\
\text { berpengaruh positif } \\
\text { terhadap employee } \\
\text { engagement. }\end{array}$ \\
\hline Mariska (2018) & $\begin{array}{l}\text { Hubungan Antara } \\
\text { Employee } \\
\text { Engagementdan } \\
\text { Kepuasan Kerja dengan } \\
\text { Kinerja }\end{array}$ & $\begin{array}{l}\text { Analisis } \\
\text { Regresi } \\
\text { Sederhana }\end{array}$ & $\begin{array}{l}\text { Hasil penelitian } \\
\text { menunjukan bahwa ada } \\
\text { hubungan yang } \\
\text { signifikan antara } \\
\text { employee } \\
\text { engagementdan } \\
\text { kepuasan kerja dengan } \\
\text { kinerja. }\end{array}$ \\
\hline
\end{tabular}

\section{Kerangka Pemikiran Konseptual}

Kerangka pikir dalam suatu penelitian merupakan suatu hal yang penting untuk dipaparkan. Berdasarkan teori serta hasil penelitian terdahulu yang telah dikemukakan diawal, kerangka pemikiran penelitian ini dimuat pada Gambar 1.

Kerangka pemikiran dilandasi untuk melihat keterikatan karyawan (employee engagement) di perusahaan tempatnya bekerja dan faktor-faktor kepuasan kerja karyawan. Keterikatan karyawan menurut Gallup (2006), terbagi menjadi enganged, not engaged, dan actively disengaged, sehingga dapat mengetahui dan menganalisis level keterikatan karyawan di tempatnya bekerja dan faktor yang digunakan untuk mengukur tingkat employee 


\section{Windy Putri Arianti \\ Musa Hubeis \\ Herien Puspitawati}

engagement. Sifat dari kepuasan kerja tidak hanya tergantung dari satu faktor melainkan dari banyak faktor seperti promosi, paket penggajian, pengawasan, pekerjaan, tim kerja dan kondisi kerja secara umum yang akan meningkatkan ataupun menyebabkan terjadinya employee engagement pada perusahaan (Vokić \& Hernaus, 2015). Pengukuran kepuasan kerja terdiri dari lima aspek, yaitu pekerjaan, gaji, promosi, supervisi, dan rekan kerja (Luthans, 2006).

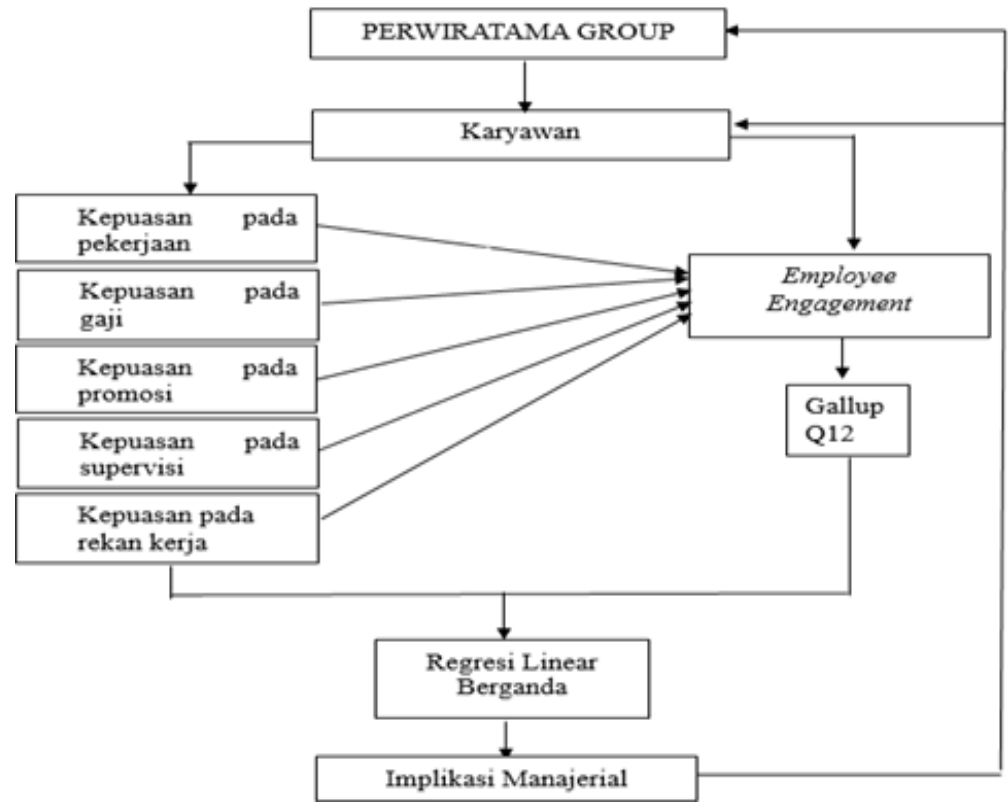

Gambar 1.

Kerangka Pemikiran Konseptual

Berdasarkan kerangka pemikiran teoritis tersebut, maka hipotesis penelitian yang diajukan adalah:

$\mathrm{H}_{1}$ : Kepuasan kerja pada pekerjaan berpengaruh terhadap Employee Engagement

$\mathrm{H}_{2}$ : Kepuasan kerja pada gaji berpengaruh terhadap Employee Engagement

$\mathrm{H}_{3}$ : Kepuasan kerja pada promosi berpengaruh terhadap Employee Engagement

$\mathrm{H}_{4}$ : Kepuasan kerja pada supervisi berpengaruh terhadap Employee Engagement

$\mathrm{H}_{5}$ : Kepuasan kerja pada rekan kerja berpengaruh terhadap Employee Engagement

\section{METODE}

\section{Lokasi dan Waktu Penelitian}

Penelitian dilakukan di empat bisnis unit perusahaan Perwiratama Group. Pengambilan data dimulai pada bulan Oktober sampai dengan Januari 2019. 


\section{Pengumpulan Data}

Metode penelitian yang digunakan dalam penelitian ini adalah metode kuantitatif yang didukung dengan metode kualitatif seperti kuesioner dan wawancara dengan beberapa informan (manajer SDM). Maholtra (2010) berpendapat bahwa kelebihan dari kuesioner dan data yang diperoleh, dapat dipercaya, karena tanggapan terbatas pada alternatif yang ditanyakan. Kuesioner diberikan kepada responden dengan online survey, yaitu salah satu cara pengumpulan data dalam survei yang dilakukan dengan web atau email.

\section{Jenis dan Sumber Data}

Jenis data yang digunakan dalam penelitian, meliputi:

1. Data primer, yaitu data yang diperoleh langsung dari responden melalui kuesioner mengenai employee engagement dan faktor-faktor kepuasan kerja

2. Data sekunder, yaitu data yang diperoleh dari perantara, dimana umumnya berupa dokumentasi perusahaan, jurnal, maupun buku-buku yang memuat teori relevan yang mendukung penelitian.

\section{Teknik Pemilihan Responden}

Populasi penelitian adalah seluruh karyawan Perwiratama Group yang berjumlah 84 orang. Teknik pengambilan contoh yang digunakan adalah teknik sampling jenuh (sensus). Sampling jenuh adalah teknik penentuan contoh, bila semua anggota populasi digunakan sebagai contoh (Sugiyono, 2002).

\section{Definisi Operasional dan Pengukuran Peubah}

Peubah yang diteliti adalah employee engagement dan faktor-faktor kepuasan kerja yang terdiri dari kepuasan pada pekerjaan, kepuasan pada gaji, kepuasan pada promosi, kepuasan pada supervisi, dan kepuasan pada rekan kerja.

1. Employee engagement diukur dengan cara meminta responden memberikan penilaian terhadap Q12 pernyataan dari Gallup Organization (2006), yaitu:

a. Mengetahui apa yang diharapkan pekerjaan,

b. Memiliki peralatan dan materi-materi yang dibutuhkan untuk mengerjakan pekerjaan dengan baik,

c. Memiliki kesempatan dalam bekerja, yaitu mengerjakan apa yang dikerjakan secara baik setiap hari,

d. Menerima penghargaan atau pujian, karena mengerjakan pekerjaan dengan baik,

e. Adanya kepedulian supervisor atau seseorang dalam lingkungan kerja, di mana saya sebagai individu,

f. Adanya orang di tempat kerja mendorong perkembangan individu,

g. Pendapat di dengar dalam lingkungan kerja, 


\section{Windy Putri Arianti \\ Musa Hubeis \\ Herien Puspitawati}

h. Misi dan tujuan perusahaan membuat pekerjaan penting,

i. Perasaaan rekan sejawat atau rekan kerja memiliki komitmen untuk melakukan pekerjaan bermutu,

j. Mempunyai teman baik di lingkungan kerja,

k. Seseorang membicarakan atau menanyakan tentang perkembangan saya,

I. Memiliki keuntungan untuk belajar dan tumbuh dalam lingkungan kerja.

Penilaian diberikan dalam bentuk skala dari 1-4 (kontinu) yang terdiri dari, 1 = Sangat Tidak Setuju (STS), 2 = Tidak Setuju (TS), 3 = Setuju (S), dan 4 = Sangat Setuju (SS).

2. Kepuasan pada pekerjaan diukur dengan cara meminta responden memberikan penilaian terhadap 14 pernyataan yang dibagi atas lima indikator (Luthans, 2006), yaitu:
a. Pekerjaan sangat menarik
b. Kesempatan untuk belajar hal-hal baru dalam pekerjaan
c. Tingkat tanggung jawab dalam pekerjaan
d. Pencapaian keberhasilan
e. Membuat kemajuan

Penilaian diberikan dalam bentuk skala dari 1-4 (kontinu) yang terdiri dari, 1 = Sangat Tidak Setuju (STS), 2 = Tidak Setuju (TS), 3 = Setuju (S), dan 4 = Sangat Setuju (SS).

3. Kepuasan pada gaji diukur dengan cara meminta responden memberikan penilaian terhadap 12 pernyataan yang dibagi atas lima indikator (Luthans, 2006), yaitu:
a. Gaji sesuai dengan tanggungjawab
b. Tunjangan sesuai dengan harapan
c. Gaji dan tunjangan lebih besar dari pesaing
d. Imbalan sesuai dengan usaha
e. Kenaikan gaji secara berkala

Penilaian diberikan dalam bentuk skala dari 1-4 (kontinu) yang terdiri dari, 1 = Sangat Tidak Setuju (STS), 2 = Tidak Setuju (TS), 3 = Setuju (S), dan 4 = Sangat Setuju (SS) .

4. Kepuasan pada promosi diukur dengan cara meminta responden memberikan penilaian terhadap 10 pernyataan yang dibagi atas lima indikator (Luthans, 2006), yaitu:
a. Ada tingkat kemajuan
b. Standar promosi
C. Kesempatan promosi kenaikan jabatan
d. Kesempatan promosi kenaikan gaji
e. Kenaikan promosi secara berkala

Penilaian diberikan dalam bentuk skala dari 1-4 (kontinu) yang terdiri dari, 1 = Sangat Tidak Setuju (STS), 2 = Tidak Setuju (TS), 3 = Setuju (S), dan 4 = Sangat Setuju (SS). 
5. Kepuasan pada supervisidiukur dengan cara meminta responden memberikan penilaian terhadap 16 pernyataan yang dibagi atas lima indikator (Luthans, 2006), yaitu:

a. Manajer memberi dukungan pekerjaan

b. Manajer memiliki motivasi

c. Manajer memberi kebebasan mengambil keputusan yang bertanggung jawab

d. Manajer mau mendengarkan pegawai

e. Manajer jujur dan adil

Penilaian diberikan dalam bentuk skala dari 1-4 (kontinu) yang terdiri dari, 1 = Sangat Tidak Setuju (STS), 2 = Tidak Setuju (TS), 3 = Setuju (S), dan 4 = Sangat Setuju (SS).

6. Kepuasan pada rekan kerjadiukur dengan cara meminta responden memberikan penilaian terhadap 15 pernyataan yang dibagi atas lima indikator (Luthans, 2006), yaitu:

a. Tim kerja menyenangkan

b. Teman-teman menyenangkan

c. Teman-teman kooperatif

d. Dukungan orang sekitar

e. Tidak dikucilkan

Penilaian diberikan dalam bentuk skala dari 1-4 (kontinu) yang terdiri dari, 1 = Sangat Tidak Setuju (STS), 2 = Tidak Setuju (TS), 3 = Setuju (S), dan 4 = Sangat Setuju (SS).

\section{Pengolahan dan Analisis Data}

Analisis data merupakan proses penyederhanaan data ke dalam bentuk yang lebih mudah dibaca dan diinterpretasikan. Teknik pengolahan dalam penelitian terdiri dari penelitian data kuantitatif, di mana data tersebut diolah dengan aplikasi Microsoft Excel 2010 untuk melihat data awal responden untuk masing-masing peubah secara tunggal dan untuk menganalisis model regresi linear berganda dengan software Statistical Product and Service Solutions (SPSS 21).

\section{HASIL DAN PEMBAHASAN}

Analisis regresi linier berganda dalam penelitian ini dilakukan setelah melalui uji asumsi klasik (uji normalitas, uji multikolinieritas, dan uji heteroskedastitas) pada data. Berdasarkan hasil yang diperoleh menunjukan uji asumsi klasik terpenuhi semua, sehingga data layak dan dapat digunakan untuk uji selanjutnya yaitu uji hipotesis.

\section{Uji F}

Pengujian dilakukan untuk menganalisis nilai $F$ hitung dan nilai signifikansi. Hasil dari pengujian ini tertera pada Tabel 2 yang menunjukkan nilai F didapat sebesar 13.547 dan nilai signifikasi dari hasil penelitian ini yaitu $0.000<0.05$, sehingga dapat disimpulkan bahwa peubah kepuasan pada pekerjaan, kepuasan pada gaji, kepuasan pada promosi, 


\section{Windy Putri Arianti \\ Musa Hubeis \\ Herien Puspitawati}

kepuasan pada supervisi, dan kepuasan pada rekan kerja sebagai peubah bebas yang diuji merupakan peubah yang tepat dalam memprediksi peubah employee engagement sebagai peubah terikat.

Tabel 2.

Pengaruh Faktor Kepuasan Kerja Terhadap Employee Engagement

\begin{tabular}{lcccc}
\hline \multicolumn{1}{c}{ Peubah } & $\begin{array}{c}\text { Unstandardized } \\
\text { Coefficients }\end{array}$ & $\begin{array}{c}\text { Standardized } \\
\text { Coefficients }\end{array}$ & t hit & Sig \\
\cline { 2 - 3 } $\boldsymbol{B}$ & 0.590 & $\boldsymbol{B}$ & & \\
\hline Constanta & 0.293 & 0.240 & 2.547 & 0.126 \\
Kep_Pekerjaan & 0.352 & 0.350 & 2.959 & 0.036 \\
Kep_Gaji & $(-0,196)$ & $(-0.164)$ & $(-1.320)$ & 0.004 \\
Kep_Promosi & 0.117 & 0.108 & 0.965 & 0.383 \\
Kep_Supervisi & 0.280 & 0.275 & 2.458 & 0.016 \\
Kep_Rekan & & & & \\
\hline Regression & 13.723 & & & \\
F & 0.000 & & & \\
Sig. F & 0.465 & & & \\
\hline R2 & 0.431 & & & \\
Adjusted R2 & & & & \\
\hline
\end{tabular}

Berdasarkan hasil pengolahan data yang telah dilakukan dapat dirumuskan persamaan regresi linear berganda sebagai berikut:

$$
\hat{Y}=0.59+0.29 X_{1}+0.35 X_{2}-0.19 X_{3}+0.11 X_{4}+0.28 X_{5}
$$

Keterangan:

$\hat{Y} \quad=$ Employee Engagement;

$\mathrm{X}_{1} \quad=$ Kepuasan pada pekerjaan itu sendiri;

$\mathrm{X}_{2} \quad=$ Kepuasan pada gaji;

$\mathrm{X}_{3} \quad=$ Kepuasan pada promosi;

$\mathrm{X}_{4} \quad=$ Kepuasan pada supervisi; dan

$\mathrm{X}_{5} \quad=$ Kepuasan pada rekan kerja.

Uji

Pengujian hipotesis dalam penelitian ini menggunakan uji † dengan kriteria sebagai berikut:

\section{Pengujian Hipotesis Pertama}

Pengujian hipotesis pertama, yaitu peubah kepuasan pada pekerjaan itu sendiri dengan employee engagement. Pengujian terhadap pengaruh peubah kepuasan pada pekerjaan itu sendiri terhadap employee engagement menunjukan hasil bahwa koefisien regresinya sebesar 0.293 dengan nilai signifikasi sebesar 0.036 dan nilai signifikasi yang diperoleh $<0.05$, sehingga dapat disimpulkan bahwa hipotesis pertama yang menyatakan bahwa "kepuasan pada pekerjaan itu sendiri berpengaruh positif terhadap employee engagement di Perwiratama Group" dapat diterima dan dibuktikan secara 
statistik. Nilai koefisien kepuasan pada pekerjaan itu sendiri sebesar 0.293 menjelaskan bahwa setiap adanya peningkatan satu persen peubah kepuasan pada pekerjaan itu sendiri akan terjadi kenaikan employee engagement sebesar $29.3 \%$.

Pekerjaan yang sesuai dengan kemampuan dan minat serta adanya kesempatan untuk mempelajari hal baru dapat meningkatkan engagement pegawai tersebut. Hasil penelitian yang diperoleh sesuai dengan penelitian yang dilakukan oleh Maholtra (2010), Bellani et al. (2017) bahwa pekerjaan itu sendiri dapat meningkatkan kepuasan kerja yang juga memengaruhi employee engagement. Menurut Backer (2009) seseorang merasa engaged dengan perusahaannya cenderung menunjukkan performa terbaik dikarenakan mereka menikmati pekerjaan yang dilakukannya.

\section{Pengujian Hipotesis Kedua}

Pengujian hipotesis kedua, yaitu peubah kepuasan pada gaji dengan employee engagement. Pengujian terhadap pengaruh peubah kepuasan pada gaji terhadap employee engagement menunjukan hasil bahwa koefisien regresinya sebesar 0.352 dengan nilai signifikasi sebesar 0.004 dan nilai signifikasi yang diperoleh $<0.05$, sehingga dapat disimpulkan bahwa hipotesis kedua yang menyatakan bahwa "kepuasan pada gaji berpengaruh positif terhadap employee engagement di Perwiratama Group" dapat diterima dan dibuktikan secara statistik. Nilai koefisien kepuasan pada gaji sebesar 0.352 menjelaskan bahwa setiap adanya peningkatan satu persen peubah kepuasan pada gaji akan terjadi kenaikan employee engagement sebesar $35.2 \%$.

Hal ini berarti, kenaikan gaji akan meningkatkan semangat dan motivasi kerja pegawai sehingga timbul engaged pada diri mereka untuk memberikan hasil yang terbaik kepada perusahaan. Hasil penelitian yang diperoleh sesuai dengan penelitian yang dilakukan oleh Berry (2010) bahwa gaji dapat meningkatkan kepuasan kerja yang juga memengaruhi dari employee engagement. Pernyataan bahwa gaji merupakan pertimbangan utama karyawan merasa betah untuk bekerja di sebuah perusahaan adalah bukan hal yang baru (Tifanny, 2016). Menurut Rommalla (2018) gaji yang dibayarkan oleh perusahaan dapat terdiri dari tiga komponen yaitu gaji pokok, tunjangan tetap dan tunjangan tidak tetap. Hal tersebut dapat membuat karyawan menjadi lebih loyal dan betah untuk bekerja di perusahaan tersebut (Lita, 2018).

\section{Pengujian Hipotesis Ketiga}

Pengujian hipotesis ketiga, yaitu peubah kepuasan pada promosi dengan employee engagement. Pengujian terhadap pengaruh peubah kepuasan pada promosi terhadap employee engagement menunjukan hasil bahwa koefisien regresinya sebesar -0.196 dengan nilai signifikasi sebesar 0.191 dan nilai signifikasi yang diperoleh $>0.05$, sehingga dapat disimpulkan bahwa "kepuasan pada promosi tidak berpengaruh terhadap employee engagement di Perwiratama Group". Nilai koefisien kepuasan pada promosi sebesar-0.196 menjelaskan bahwa terdapat hubungan negatif antara kepuasan pada 


\section{Windy Putri Arianti \\ Musa Hubeis \\ Herien Puspitawati}

promosi dengan employee engagement dimana setiap adanya peningkatan satu persen peubah kepuasan pada promosi akan terjadi penurunan employee engagement sebesar $19.6 \%$.

Kebijakan promosi yang berlaku saat ini tidak diimbangi dengan fasilitas yang menunjang kenaikan jabatan. Oleh karena itu, pegawai tidak terlalu antusias untuk mendapatkan promosi karena merasa promosi hanya memberikan beban pekerjaan yang lebih berat tanpa disertai peningkatan kesejahteraan. Hasil penelitian ini tidak sejalan dengan penelitian yang dilakukan oleh Kalvina dan Ludviga (2016) dan Ahmed et al. (2017) yang menyatakan bahwa kepuasan kerja pada promosi memengaruhi employee engagement. Namun, penelitian ini sejalan dengan pendapat dari Ruangshare (2016) bahwa skala perusahaan tempat karyawan tersebut bekerja dapat memengaruhi promosi. Jika skala perusahaan tersebut kecil maka peluang promosi pun tidak begitu besar sehingga tidak memengaruhi karyawan.

\section{Pengujian Hipotesis Keempat}

Pengujian hipotesis keempat, yaitu peubah kepuasan pada supervisi dengan employee engagement. Pengujian terhadap pengaruh peubah kepuasan pada supervisi terhadap employee engagement menunjukkan hasil bahwa koefisien regresinya sebesar 0.117 dengan nilai signifikasi sebesar 0.338 dan nilai signifikasi yang diperoleh $>0.05$, sehingga dapat disimpulkan bahwa "kepuasan pada supervisi tidak berpengaruh terhadap employee engagement di Perwiratama Group". Nilai koefisien kepuasan pada supervisi sebesar 0.117 menjelaskan bahwa setiap adanya peningkatan satu persen peubah kepuasan pada supervisi akan terjadi kenaikan employee engagement sebesar $11.7 \%$. Berdasarkan hasil penelitian kegiatan pengawasan belum berjalan dengan baik, namun hal tersebut tidak dipermasalahkan oleh pegawai karena mereka hanya terbebani dengan ketidakjelasan sistem perusahaan yang ada. Hasil penelitian yang diperoleh sesuai dengan penelitian yang dilakukan oleh Zikouridis (2015) yang menyatakan bahwa supervisi tidak berpengaruh terhadap employee engagement.

\section{Pengujian Hipotesis Kelima}

Pengujian hipotesis kelima, yaitu peubah kepuasan pada rekan kerja dengan employee engagement. Pengujian terhadap pengaruh peubah kepuasan pada rekan kerja terhadap employee engagement menunjukan hasil bahwa koefisien regresinya sebesar 0.280 dengan nilai signifikasi sebesar 0.016 dan nilai signifikasi yang diperoleh $<0.05$, sehingga dapat disimpulkan bahwa hipotesis kelima yang menyatakan bahwa "kepuasan pada rekan kerja berpengaruh positif terhadap employee engagement di Perwiratama Group" dapat diterima dan dibuktikan secara statistik. Nilai koefisien kepuasan pada rekan kerja sebesar 0.280 menjelaskan bahwa setiap adanya 
peningkatan satu persen peubah kepuasan pada rekan kerja akan terjadi kenaikan employee engagement sebesar $28 \%$.

Koordinasi dan kerjasama antar tim memudahkan untuk mencapai visi dan misi perusahaan serta menyelesaikan pekerjaan mereka masing-masing sehingga menimbulkan kenyamanan dalam lingkungan kerja yang pada akhirnya meningkatkan engagement pegawai. Hasil penelitian yang diperoleh sesuai dengan penelitian yang dilakukan oleh Tepayakul dan Rinthaisong (2018) bahwa rekan kerja dapat meningkatkan kepuasan kerja yang juga memengaruhi dari employee engagement. Sejalan dengan pendapat Mutia (2018) bahwa ketika karyawan memiliki hubungan yang baik dengan rekan kerja, maka mereka akan merasa lebih terkoneksi dengan perusahaan tempatnya bekerja. Begitu pun menurut Jamil (2017), untuk meningkatkan engagement dapat dilakukan dengan membangun kenyamanan dan interaksi positif sesama karyawan.

Tabel 3.

Implikasi Manajerial

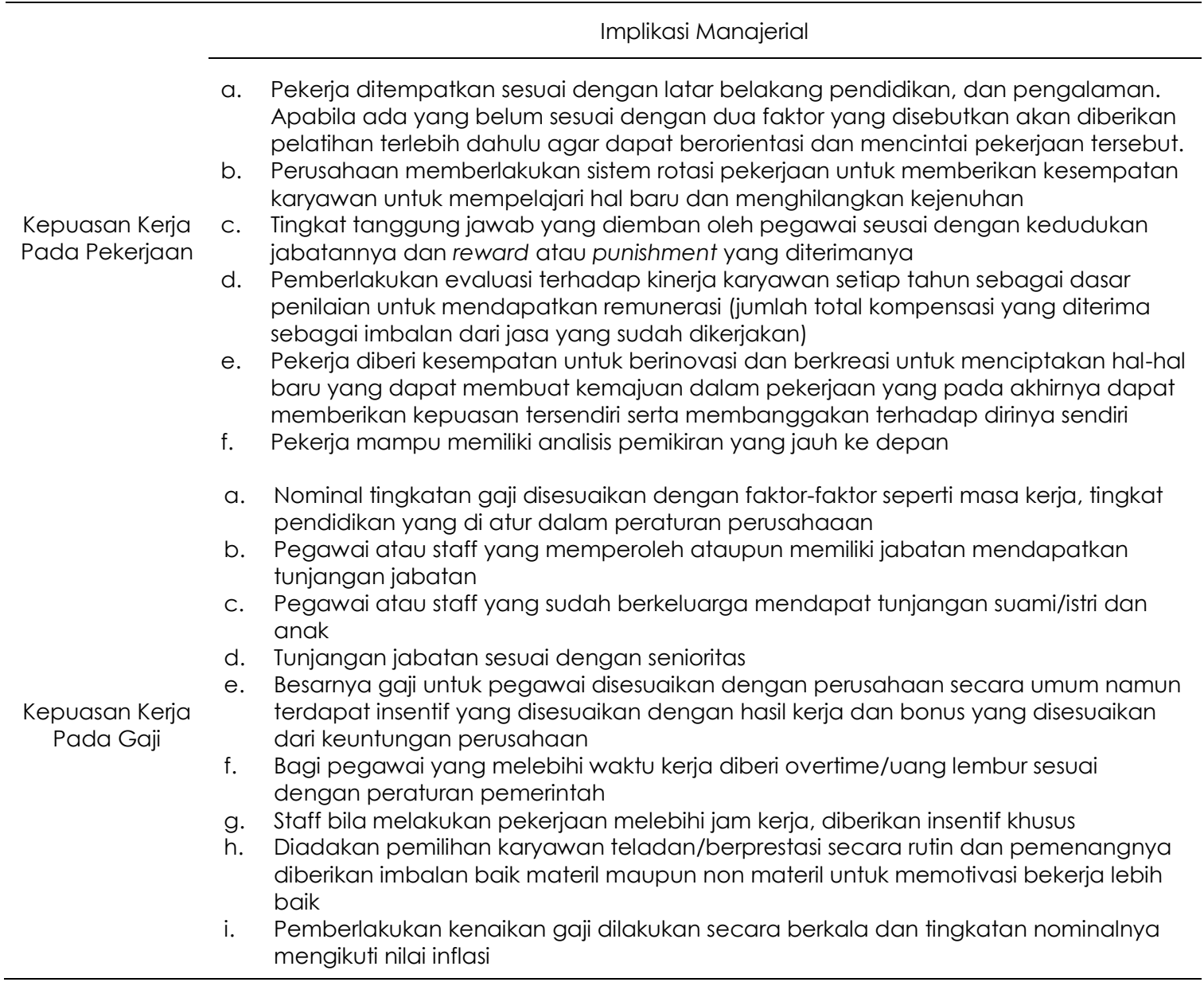




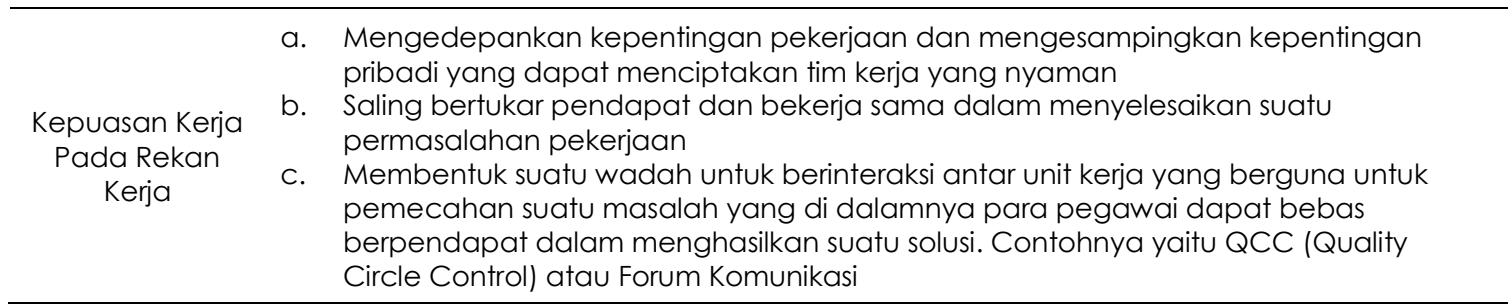

\section{Koefisien Determinasi}

Hasil dari uji koefisien determinasi Tabel 15 yaitu nilai Adjusted $R$ Square sebesar 0.431 atau sebesar $43.1 \%$, menunjukan bahwa peubah faktor kepuasan kerja (kepuasan kerja pada pekerjaan, kepuasan kerja pada gaji, kepuasan kerja pada promosi, kepuasan kerja supervisi, dan kepuasan kerja pada rekan kerja) memengaruhi peubah employee engagement di Perwiratama Group sebesar $43.1 \%$, sedangkan sisanya dipengaruhi oleh faktor lain yang tidak diteliti dalam penelitian ini.

\section{Implikasi Manajerial}

Berdasarkan hasil penelitian yang telah dilakukan, diketahui faktor kepuasan kerja (kepuasan kerja pada pekerjaan, kepuasan kerja pada gaji, kepuasan kerja pada rekan kerja) memengaruhi employee engagement di empat bisnis usaha Perwiratama Group yaitu yaitu PT Arwinda Perwira Utama, PT Cipta Ekspedisi Perwiratama, PT Solusi Pangan Perwiratama, PT Cipta Kuliner Perwiratama. Oleh sebab itu, untuk meningkatkan employee engagement, maka implikasi manajerial yang diajukan (Table 3).

\section{SIMPULAN}

Berdasarkan penelitian yang telah dilakukan, dapat disimpulkan peubah kepuasan kerja pada pekerjaan, kepuasan kerja pada gaji, dan kepuasan kerja pada rekan kerja berpengaruh positif terhadap employee engagement di Perwiratama Group. Sedangkan peubah kepuasan kerja pada promosi dan kepuasan kerja pada supervisi tidak berpengaruh terhadap employee engagement di Perwiratama Group.

\section{DAFTAR PUSTAKA}

Affini, D. N. dan Surip, N. 2018. Pengaruh Kompensasi dan Kepuasan Kerja Terhadap Employee Engagement yang Berdampak Pada Turnover Intentions. Jurnal IImiah Manajemen Bisnis 4(1): 113-127.

Ahmed, S., Faiz B. A., dan Abdul R. J. 2017. Influence of Employee Engagement on Employee Promotion Opportunity and Performance Relationship in Developing Context: Critical Evaluation with PLS-SEM Analysis Technique. Transylvanian Review 25 (17): 4827-4840. 
Anggraini, L., Endang, S. A., dan Arik, P. 2016. Faktor-faktor yang mempengaruhi employee engagement generasi Y (studi pada karyawan PT Unilever Indonesia Tbk-Surabaya. Jurnal Administrasi Bisnis (JAB) 37(2):183-191.

Backer, A. B. 2009. Building Engagement in the Workplace: The Peak Performing Organization. In R. J. Nurke \& C. L. Cooper (Eds.) Oxon (UK): Routledge.

Bellani, E., Sri, R. R. dan Muhammad, T. 2017. Job Satisfaction as a Predictor Employee Engagement. 8th International Conference of Asian Association of Indigenous and Cultural Psychology 12(7):15-19.

Berry, M. L. 2010. Predicting Turnover Intent: Examining the Effects of Employee Engagement, Compensation Fairness, Job Satisfaction, and Age. Tennessee (KV): The University of Tennessee, Knoxville.

Coffman, C., Gonzalez-Molina, G., Miller, J., dan Tucker, K. A. 2002. Follow this Path: How The World's Greatest Organizations Drive Growth by Unleashing Human Potential. New York: Warner Books.

Fleming, J. H. dan Asplund, J. 2007. Human Sigma: Managing the employee-customer encounter. New York (NY): Gallup Press.

Gallup, S. 2006. Engaged Employees Inspire Company Innovation. France (FR): Gallup Management Journal.

Garg, K., Dar, I. A., dan Mishra, M. 2018. Job Satisfaction and Work Engagement: A Study Using Private Sector Bank Managers. SAGE 20(1): 58-71.

Jamil, A. 2017. 3 hal yang bisa meningkatkan engagement dalam bekerja. [internet]. [diakses 2019 Agustus 25]. Tersedia pada: https://www.kubikleadership.com/3-halyang-bisa-meningkatkan-engagement-dalam-bekerja/.

Kaliannan. M. dan Adjovu, S N. 2015. Effective employee engagement and organizational success: a case study mobile telecommunication network in Ghana. ProcediaSocialand Behavioral Sciences 172: 161-168.

Kalvina, I., dan Ludviga, A. 2016. Exploring the Relationships between job satisfaction, work engagement, and loyalty of academic staff. International Journal of Economics and Management Engineering 10(1): 99-105.

Katili, P. B., dan Adriana, W. S. H. 2017. Analisis pengaruh employee competence, job satisfaction dan employee engagement terhadap employee performance. Journal Industrial Servicess 3(1): 20-25.

Kari, A. 2013. The Effect of Job Satisfaction and Motivation on Employee Engagement of Administrative Staff of Bandung State Polytechnic. Jurnal IImu Manajemen \& Bisnis 1(4):1-15.

Kertiasih, N. R. R., Sujana, I. W., dan Suardika, I. N. 2018. The Effect of Leadership Style to Job Satisfaction, Employee Engagement and Employee Performance (Study at PT. 


\section{Windy Putri Arianti \\ Musa Hubeis \\ Herien Puspitawati}

Interbat, Bali, Nusra, and Ambon). International Journal of Contemporary Research and Review 9(3): 20592-20600.

Lita. 2018. 10 alasan pentingnya perusahaan memberi tunjangan untuk karyawan. [internet]. [diakses 2019 Agustus 25]. Tersedia pada: https://www.sewakantorcbd.com/blog/10 alasan-pentingnya-perusahaan-memberi-tunjangan-untuk-karyawan/.

Luthans, F. 2006. Perilaku Organisasi 10 th. Edisi Terjemahan Indonesia. Yogyakarta (ID): Penerbit ANDI.

Maarif, M. S. dan Lindawati, K. 2014. Manajemen Pelatihan: Upaya Mewujudkan Kinerja Unggul dan Pemahaman Employee-Engagement. Bogor (ID): IPB Press.

Macey, W. H., Schneider, B., Barbera, K. M., dan Young, S. A. 2009. Employee EngagementTools for Analysis, Practice, and Competitive Advantage. College Park (US): WileyBlackwell.

Maholtra, N. 2010. Marketing Research: An Applied Orientation. New Jersey (US): Harper and Row.

Mariska, D. D. 2018. Hubungan antara employee engagement dan kepuasan kerja dengan kinerja. Jurnal Insight Fakultas Psikologi Universitas Muhammadiyah Jember 14(1):9198.

Mujiasih, E. dan Ratnaningsih, I. F. 2011. Kepemimpinan Transformasional dan Employee engagement - Universitas Diponegoro Solo. Seminar Nasional Peran Psikologi Dalam Boundaryless Organization 184(4): 1-14.

Mutia, I. R. 2018. Bagaimana partner kerja akan sangat berpengaruh dengan kinerjamu? [internet]. [diakses 2019 Agustus 25]. Tersedia pada: https://glints.com/id/lowongan/ pengaruh-partner-kerja-pada-kinerja/.

Robbins, S. P. dan Timothy, A. J. 2015. Perilaku Organisasi. Edisi Bahasa Indonesia. Jakarta (ID): Salemba Empat.

Rommalla, S. 2018. Perbedaan tunjangan tetap dengan tunjangan tidak tetap dalam penggajian. [internet]. [diakses 2019 Agustus 25]. Tersedia pada: https://www.gadjian .com/blog/2018/01/17/perbedaan-tunjangan-tetap-dengan-tunjangan-tidak-tetapdalam-penggajian/.

Ruangshare. 2016. Karir tak kunjung meningkat mungkin ini penyebabnya. [internet]. [diakses 2019 Agustus 08]. Tersedia pada: https://ruangshare.com/2016/04/10/karir-takkunjung -meningkat-mungkin-ini-penyebabnya/.

Sugiyono. 2012. Metode Penelitian Kuantitatif, Kualitatif dan R\&D. Bandung (ID): Alfabeta.

Susilo, S, dan Abdul, M. 2015. Kepemimpinan Transformasional, Kepuasan Kerja dan Komitmen Organisasi. Persona Jurnal Psikologi Indonesia 4(3): 304-313. 
Tepayakul, R., dan Rinthaisong, I. 2018. Job satisfaction and employee engagement among Human resources staff of thai private higher education institutions. The Journal of Behavioral Science 13(2): 68-81.

Tifanny. 2016. Ternyata 10 alasan membuat karyawan betah bekerja di sebuah perusahaan. [internet]. [diakses 2019 Agustus 25]. Tersedia pada: https://www.moneysmart.id/ ternyata-10-alasan-membuat-karyawan-betah-bekerja-perusahaan/.

Umar, H. 2014. Manajemen Riset dan Perilaku Konsumen. Jakarta (ID): PT Gramedia.

Vokić, N. P., dan Hernaus, T. 2015. The triad of job satisfaction, work engagement and employee loyalty-the interplay among the concepts. EFZG Working Paper Series 15(7):1-13.

Vorina, A., Simonic, M., dan Vlasova, M. 2017. An analysis of the relationship between job satisfaction and employee engagement. Economic Themes 55(2):243-262.

Wibowo. 2015. Perilaku dalam Organisasi edisi kedua. Jakarta (ID): Rajawali Pers.

Yuswardi. 2019. Analisis Faktor-Faktor yang Mempengaruhi Keterikatan Karyawan pada Hotel Berbintang di Batam. Jurnal Ekonomi \& Ekonomi Syariah 2(2):194-205.

Zikouridis, F. 2015. Employee engagement and job satisfaction: a research between their relationship in a real context. Thessalloniki (GR): International Hellenic University. 